\title{
Three new spider species of the family Thomisidae from Hong Kong (Arachnida: Araneae)
}

\author{
Xiang Xu, Xu Han \& Shuqiang Li
}

Xu, X., Han, X. \& Li, S. 2008: Three new spider species of the family Thomisidae from Hong Kong (Arachnida: Araneae). — Entomol. Fennica 19: 13-17.

Three new species of spiders from farmland and nearby non-crop fields at Tai Lung Experimental Station (TLES), Hong Kong, were discovered. All three new species occurred in the family Thomisidae, they are Diaea simplex Xu, Han \& Li sp. n., Massuria bellula Xu, Han \& Li sp. n. and Mastira tegularis Xu, Han \& Li sp. n. Descriptions and illustrations of the new species are provided.

X. Xu, Institute of Zoology, Chinese Academy of Sciences, Beijing 100101, China; sansanxu@163.com

X. Han, Department of Integrative Biology, University of Guelph, Guelph, Ontario N1G2W1, Canada; hanx@uoguelph.ca

S. Li, Institute of Zoology, Chinese Academy of Sciences, Beijing 100101, China; corresponding author's e-mail: lisq@ioz.ac.cn

Received 17 January 2007, accepted 21 March 2007

\section{Introduction}

Hong Kong is located in a wide transition zone between the Palaearctic and Oriental regions. $\mathrm{Xu}$ \& Li (2006) reported that Palaearctic species comprise $30 \%$ of the spider fauna in Hong Kong. Although Platnick (2007) reported a total of 24 families and 148 species of spiders in this area, the biodiversity of spiders is not well known. Further study of the spiders of Hong Kong would facilitate construction of an accurate taxonomy, an exploration of biogeographic patterns and potentially a predictive framework for establishing priorities for conservation.

Recently, we examined a collection of spiders taken from farmland fields and nearby non-crop fields at the Tai Lung Experimental Station (TLES), Sheung Shui, Hong Kong. The only government farmland in Hong Kong, the TLES serves to help farmers with plant husbandry and protection. The station occupies 19.8 ha and pri- marily consists of established orchards, open fields and greenhouses for experimental use. Our examination of the collection revealed three new species of spiders.

\section{Materials and methods}

Spiders were collected by Mr. Ping-wing Chan and Mr. Chi-keung Johnny Pun, of the Agriculture, Fisheries and Conservation Department, Hong Kong and preserved in $70 \%$ alcohol. Specimens were examined and measured under an SZ11-Olympus stereomicroscope and an Olympus BX41 compound microscope. All illustrations were made using a camera lucida. Male palps and female epigyna were examined and illustrated after they were dissected from the spiders' bodies. Vulvae of female epigyna were cleared in boiling solution of $\mathrm{KOH}$, which dissolved non-chitinous tissues. Male palps and 
epigyna were immersed in $75 \%$ alcohol for microscopic examination.

Anatomical nomenclature follows Platnick (2007). The leg measurements are given in the following sequence: Total (femur, patella, tibia, metatarsus, tarsus). All measurements are in millimeters. Terminology for the somatic morphology and genital structures follows Ono (1988). All the type material is deposited in the Institute of Zoology, Chinese Academy of Sciences in Beijing, China.

Abbreviations used in the description are as follows: AER - anterior eye row; ALE - anterior lateral eye; AME - anterior median eye; AMEALE - distance between AME and ALE; AMEAME - distance between AMEs; ITA - intermediate tibial apophysis of male palp; MOA - median ocular area; MOA-L - length of MOA; MOA-WA - anterior width of MOA; MOA-WPposterior width of MOA; PER - posterior eye row; PLE - posterior lateral eye; PME - posterior median eye; PME-PLE - distance between PME and PLE; PME-PME - distance between PMEs; RTA - retrolateral tibial apophysis of male palp; TL - total length; VTA - ventral tibial apophysis of male palp.

\section{Taxonomy}

\subsection{Diaea simplex}

\section{Xu, Han \& Li sp. n. (Fig. 1)}

Material examined. Holotype $\curvearrowright$, China: on leaf, Tai Lung Experimental Station, Hong Kong, 7.VII.1999, Ping-wing Chan. Paratype: $1 \delta$, collected together with the holotype.

Description. Total length: 4.37-4.53. TL of holotype 4.53. Prosoma: 2.13 long, 2.13 wide. Opisthosoma: 2.40 long, 1.90 wide. Prosoma (length/width 1.00) not flat but slightly raised, orange colored, covered with short setae (Fig. 1a). AER strongly recurved, PER recurved. Tubercles of ALE and PLE much developed and slightly separated. ALE $>\mathrm{AME}=\mathrm{PLE}>\mathrm{PME}$, ALE/AME 1.47, PLE/PME 1.07, AME-AME/ AME-ALE 1.43, PME-PME/PME-PLE 0.77, MOA-WA/WP 1.00, MOA- L/W 1.00, clypeus/ AME-AME 1.30, clypeus nearly vertical. Chelicera toothless. Sternum (length/width 1.07)

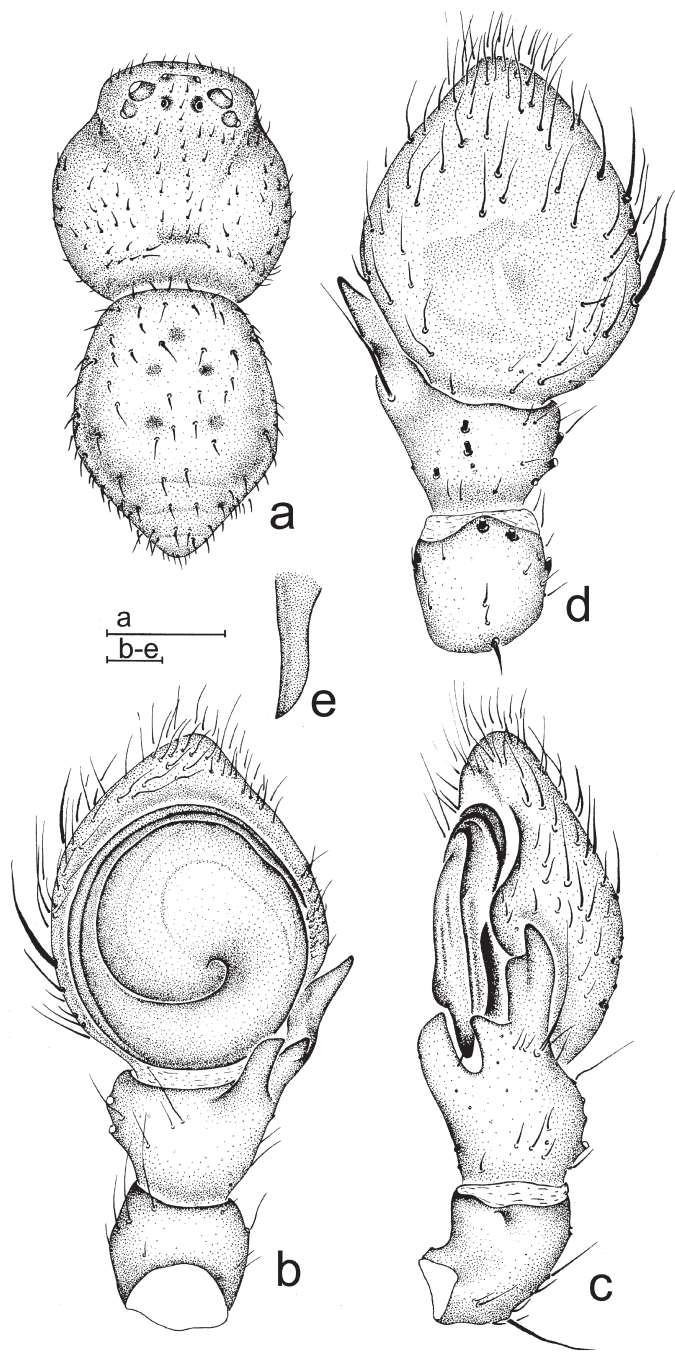

Fig. 1. Diaea simplex sp. n., holotype ${ }^{\lambda}$. - a. Body, dorsal view. - b. Left male palp, ventral view. - c. Left male palp, retrolateral view. $-d$. Left male palp, dorsal view. - e. Distal end of embolus. Scale bars: $a=1.0$; $\mathrm{b}-\mathrm{e}=0.1 \mathrm{~mm}$.

nearly as long as wide, labium (length/wide 1.67) much longer than wide. Setae of legs well developed. Lengths of legs: I $9.00(2.67+1.20+2.13+$ $2.00+1.00)$, II $8.96(2.73+1.20+2.17+1.93+$ $0.93)$, III $4.47(1.47+0.67+1.00+0.80+0.53)$, IV $4.53(1.47+0.63+1.00+0.83+0.60)$. Leg formula: I, II, IV, III. Opisthosoma (length/ width 1.26) weakly sclerotized, longer than wide, and the posterior half gradually becoming sharp. 5 distinct muscle markings located on the anterior 
Fig. 2. Massuria bellula sp. n., holotype + . - a. Body, dorsal view. - b. Epigunum, ventral view. - c. Epigunum, dorsal view. Scale bars: $\mathrm{a}=1.0 ; \mathrm{b}, \mathrm{c}=0.1 \mathrm{~mm}$.

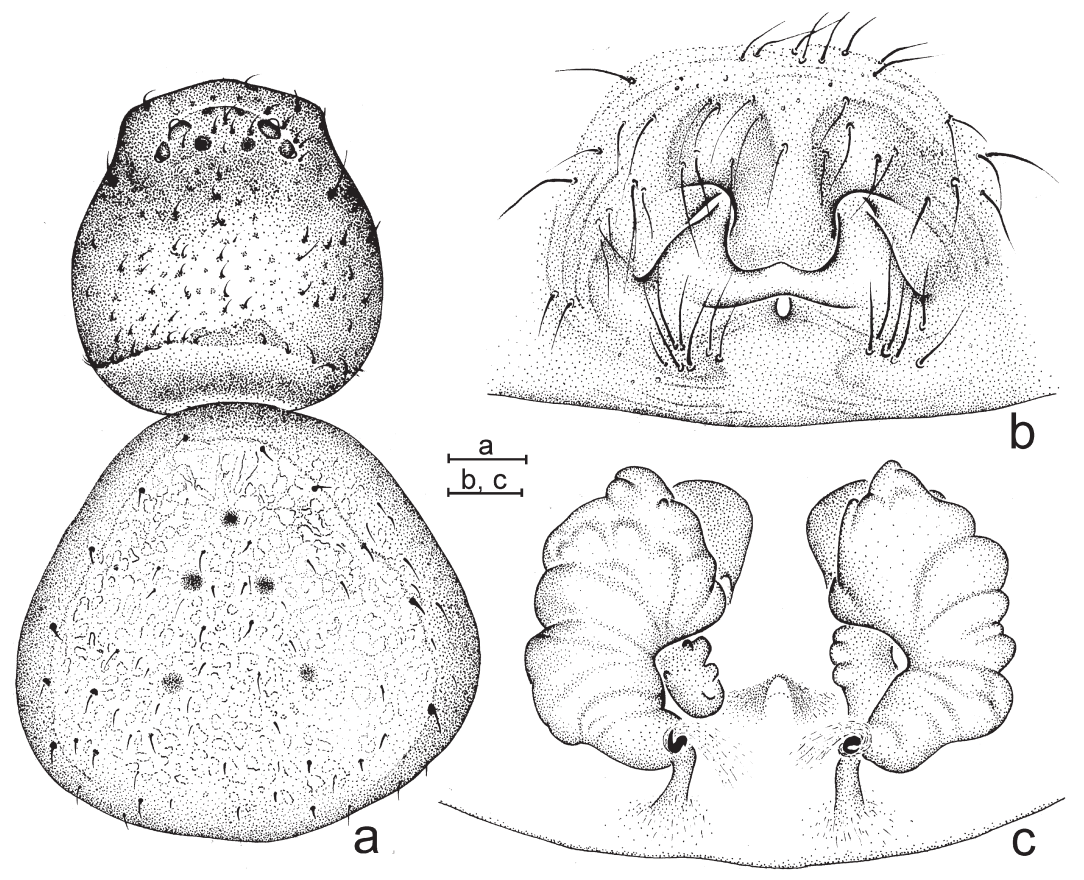

half of the dorsum (Fig. 1a). Ventral opisthosoma without pattern.

Spiniformation of legs of holotype. femur: I dorsal 1-1-2-2-1-1-0, II dorsal 1-1-1-1-0-1, III dorsal 0-1-1-0-0-1, IV dorsal 0-1-1; patella: I-III dorsal 1-0-1, IV dorsal 1-0-1, retrolateral 1; Tibia: I- II ventral 2-2, dorsal 1-1, III dorsal 1-1, IV dorsal 1-1, prolateral $0-1$, retrolateral $0-1$; Metatarsus: I ventral 0-1-2-0-2-2-2 ap, 1-1-2-02-2-2 ap (right leg), prolateral 1 ap, II ventral 0-22-0-1-2-2 (right leg), 0-0-2-0-2-2-0, prolateral 1 ap.

Male palp. Tibia with VTA, ITA and RTA. RTA with sharp distal end. ITA distinct. VTA strong (Fig. 1b-c). Bulb very simple, slightly convex (Fig. 1b). Embolus broad not only at the base but also in the distal end, winding less than 1.0 time around the tegulum (Fig. 1b-e).

Distribution. China (Hong Kong).

Diagnosis. This new species can be distinguished from Diaea livens Simon, 1876 by the slightly sclerotized opisthosomal dorsum, the distinct ITA and the short distance between RTA and ITA. This new species also differs from Diaea subdola O.P.-Cambridge, 1885 (Song et al. 1997) in having a strongly developed ITA and a large tip on the VTA (Fig. 1a-c).
Etymology. The specific name refers to the simple structure of the bulb of male palp (Latin: simplex - simple); adjective.

\subsection{Massuria bellula \\ Xu, Han \& Li sp. n. (Fig. 2)}

Material examined. Holotype ${ }_{+}$, China: on leaf, Tai Lung Experimental Station, Hong Kong, 30.VI.1999, Ping-wing Chan. Paratype: 1 , , collected together with the holotype.

Description. Total length: 9.55-12.84. TL of holotype 9.55. Prosoma: 4.03 long, 3.88 wide. Opisthosoma: 5.52 long, 5.67 wide. Prosoma (length/width 1.04) covered with many green dots except for eye region, each dot with one seta (Fig. 2a). AER strongly recurved, PER slightly recurved. Tubercles of all eyes white, tubercles of ALE and PLE strongly developed and distinctly separated. ALE $>$ PLE $>$ AME $>$ PME, ALE/AME 1.45, PLE/PME 1.25, AME-AME/AME-ALE 1.55, PME-PME/PME-PLE 0.76, MOA-WA/ WP 1.04, MOA- L/W 1.00, clypeus/AME-AME 1.39 , clypeus nearly vertical. Chelicera toothless, with green dots on the dorsum as prosoma. Sternum (length/width 1.20) covered short white 
hairs. Labium (length/width 1.88) much longer than wide. Palpal tarsus, tibia and patella with many setae. Lengths of legs: I $11.44(3.60+1.47+$ $2.67+2.47+1.23)$, II $13.53(4.13+2.00+3.20+$ $2.80+1.40)$, III $7.99(2.67+1.33+1.73+1.53+$ $0.73)$, IV $8.28(2.67+1.27+1.87+1.67+0.80)$. Leg formula: II, I, IV, III. Opisthosoma (length/ width 0.97) pyriform. Dorsal opisthosoma yellow or yellowish white, covered with setae and many irregular silvery white patterns, and with 5 brown markings distinct (Fig. 2a). Ventral opisthosoma also covered with silvery white patterns.

Spiniformation of legs of holotype. femur: I dorsal 0-0-1-1-0, prolateral 1-1-1-1-0-0-0, II dorsal 1-0; patella: I-II dorsal 1-1 ap, III dorsal 1-1, IV dorsal 1-1 ap, prolateral 1; tibia: I ventral 0-02-2-2-3-2, II dorsal 1-1, ventral 0-2-0-2-2-0-2-21-2 ap, prolateral 0-0-1, retrolateral 0-0-1, III dorsal 1-1-2, ventral 1, IV dorsal 1-1; metatarsus: I ventral 0-2-2-0-2-2-2 ap, prolateral 0-1-1-1 ap, retrolateral 1-0-0, II ventral 0-2-1-2-2-1-2-2-2 ap, prolateral 0-1-1-1 ap, retrolateral 1-1.

Female genitalia. Epigynum with a nosewing-shaped sclerotized plate. Central hood present under the sclerotized plate (Fig. 2b). Spermathecae slightly kidney-shaped, and with many small tubercles and shallow grooves. Intromittent duct broad and flat, hidden by the spermathecae and only partly visible (Fig. 2c).

Distribution. China (Hong Kong).

Diagnosis. This new species can be easily separated from Massuria angulata Thorell, 1887 by the sclerotized, nosewing-shaped epigynal plate (Fig. 2b) and the longitudinally extended spermathecae (Fig. 2c).

Etymology. The specific name is derived from the Latin "bellulus", meaning "lovely"; adjective.

\subsection{Mastira tegularis Xu, Han \& Li sp. n. (Fig. 3)}

Material examined. Holotype $\widehat{\jmath}$, China: Tai Lung Experimental Station, Hong Kong, 12.X.1999, Ping-wing Chan. Paratype: $1 \hat{\jmath}$, collected together with the holotype.

Description. Total length: 2.13-2.16. TL of holotype 2.16. Prosoma: 1.03 long, 1.07 wide. Opisthosoma: 1.13 long, 1.03 wide. Prosoma

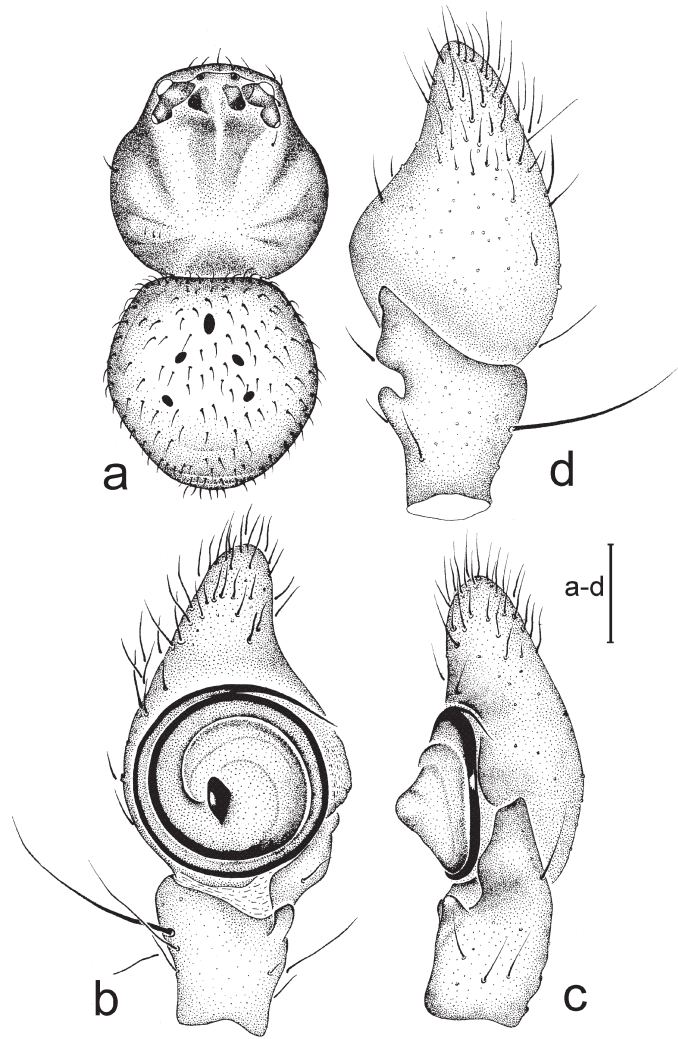

Fig. 3. Mastira tegularis sp. n., holotype ô. - a. Body, dorsal view. - b. Left male palp, ventral view. - c. Left male palp, retrolateral view. $-d$. Left male palp, dorsal view. Scale bars: $a=0.5 ; b-d=0.1 \mathrm{~mm}$.

(length/width 0.96 ) orange colour. Head with strong setae and thoracic region with short setae (Fig. 3a). AER and PER recurved. Tubercles of all eyes black. Tubercles of ALE and PLE strongly developed, connate. ALE $>$ PLE $>$ AME $=$ PME, ALE/AME 2.00, PLE/PME 1.50, AMEAME/AME-ALE 1.25, PME-PME/PME-PLE 1.14, MOA-WA/WP 0.79, MOA- L/W 1.20, clypeus/AME-AME 1.40. Chelicerae without any tooth, maxillae (length/width 1.00) and sternum (length/wide 1.13) light yellow. Setae of legs and claw tufts weakly developed. Legs without any annuli. The patellae, tibiae and metatarsusi of leg I- II reddish and other parts of legs I-IV yellow. Lengths of legs: I $4.55(1.35+0.55+1.10+$ $0.95+0.60)$, II $4.43(1.25+0.55+1.15+0.90+$ $0.58)$, III $2.05(0.60+0.30+0.50+0.35+0.30)$, IV $2.20(0.70+0.30+0.50+0.40)$. Leg formula: I, II, IV, III. Opisthosoma (length/width 1.10) widest 
in the middle. The dorsum of opisthosoma covered with short setae, and with 5 distinct muscle markings (Fig. 3a).

Spiniformation of legs of holotype. femur: I dorsal 2-2-1-1-0, II dorsal 1-1-1-0-0-1, III dorsal 0-1-1-0-0-1, IV dorsal 1; Tibia: I-II ventral 0-0-2, III dorsal 1-1; Metatarsus: I ventral 0-1-2-2 ap, II ventral $0-0-0-2-1$.

Male palp. Tibia with VTA and RTA. VTA not much developed. RTA strong, with broad distal end (Fig. 3c-d). Bulb with median apophysis like a roof tile (Fig. 3b). Embolus very long, winding 1.5 times around the tegulum (Fig. 3b-c).

Distribution. China (Hong Kong).

Diagnosis. The species is similar to $M$. bipunctata Thorell, 1891, but can be easily distinguished by: 1) embolus of this new species is anteriorly origined (Fig. 3b), but in M. bipunctata it is posteriorly origined; 2) the differences in shape of their median apophysis (Fig. 3b). This new species can also distinguished from $M$. flavens (Thorell 1877) by the strong RTA and the roofshaped median apophysis (Fig. 3b-c).

Etymology. The specific name is an adjective derived from the Latin noun "tegula", meaning "roof tile". It refers to the roof tile-like median apophysis of the male palp.
Acknowledgments. The manuscript benefited greatly from comments from Prof. Robert W. Murphy (University of Toronto, Canada), Dr. Pekka T. Lehtinen (University of Turku, Finland), Dr. Hirotsugu Ono (National Science Museum, Japan), Dr. Xinping Wang (University of Florida, USA), and two anonymous referees. We are grateful to Mr. Ping-wing Chan, Mr. Chi-keung, Johnny Pun and Mr. Yue Hong, Stephen Lai for supplying specimens, and to Dr. Bernhard A. Huber (Zoologisches Forschungsinstitut und Museum Alexander Koenig, Germany) for the loan of Diaea livens Simon, 1876. This study was supported by the National Natural Sciences Foundation of China (NSFC-30670239, 30470213, 30499341), by the National Science Fund for Fostering Talents in Basic Research (Special subjects in animal taxonomy, NSFCJ0630964/J0109), by the Knowledge Innovation Program of Chinese Academy of Sciences (KSCX2-YW-Z-008, KSCX3-IOZ-0614) and partly also by the Beijing Natural Science Foundation (6052017).

\section{References}

Ono, H. 1988: A revisional study of the spider family Thomisidae (Arachnida, Araneae) of Japan. - National Science Museum, Tokyo. ii +252 pp.

Platnick, N. I. 2007: The world spider catalog, version 7.5. American Museum of Natural History. [www document]. URL http://research.amnh.org/entomology/ spiders/catalog/index.html (accessed: 1.III.2007).

Song, D. X. \& Zhu, M. S. 1997: Fauna Sinica: Arachnida: Araneae: Thomisidae, Philodromidae. - Science Press, Beijing. 259 pp. [In Chinese]

Xu, X. \& Li, S. 2006: Study on spider fauna of Hong Kong. — Acta Arachnol. Sin. 15(1): 27-32. [In Chinese] 